\title{
Aspectos fisiológicos da toxidez de ácidos orgânicos em sementes de aveia
}

\author{
Lilian Madruga de Tunes* \\ Franciéle Olivo \\ Pablo Gerzson Badinelli \\ Alexandra Cantos \\ Antonio Carlos Souza Albuquerque Barros
}

\author{
Universidade Federal de Pelotas \\ Faculdade de Agronomia Eliseu Maciel \\ Caixa Postal 354, CEP 96001-970, Pelotas -RS, Brasil \\ *Autor para correspondência \\ lilianmtunes@yahoo.com.br
}

Submetido em 31/03/2008

Aceito para publicação em 05/08/2008

\section{Resumo}

Para que o cultivo da aveia (Avena sativa L.) seja também alternativo economicamente viável em solos de várzea, faz-se necessário a utilização de cultivares tolerantes aos principais ácidos orgânicos produzidos pela decomposição da matéria orgânica gerada em cultivos com plantio direto. O objetivo deste trabalho foi determinar a faixa de concentração e as respostas fisiológicas para serem utilizadas na cultivar UPF 16 para tolerância a ácidos orgânicos. Foram estudados os efeitos de cinco concentrações dos três principais ácidos formados no solo: ácido acético $(0 ; 4 ; 8 ; 12$ e $16 \mathrm{mM})$, ácido propiônico $(0 ; 4 ; 8 ; 12$ e $16 \mathrm{mM})$ e ácido butírico $(0 ; 2 ; 4 ; 8$ e 12mM). Os testes realizados foram o de germinação, comprimento da parte aérea, comprimento da raiz, massa seca da parte aérea e massa seca da raiz. Pelos resultados verifica-se que a variável comprimento de raízes foi a mais responsiva em todos os ácidos e que o nível crítico de toxidez do ácido acético, propiônico e butírico que reduziu $50 \%$ o comprimento da raiz foi de 9,$0 ; 6,5$ e $3,0 \mathrm{mM}$, respectivamente.

Unitermos: Avena sativa L., sementes, ácidos orgânicos, toxidez

\section{Abstract}

Physiological aspects of toxicity of organic acids to oat seeds. For the cultivation of oats (Avena sativa L.) as an alternative which is economically viable in flooded soils, it is necessary to use cultivars that are tolerant to the main organic acids produced by the decomposition of the organic matter generated when cultivating areas by direct seeding. The objective of this work was to determine the concentration rates and physiological stimuli necessary for use in the cultivar UPF 16 for tolerance to organic acids. We studied the effects of five concentrations of the three main acids formed in the soil: acetic acid $(0,4,8,12$ and $16 \mathrm{mM})$, propionic acid $(0,4,8,12$ and $16 \mathrm{mM})$ and butyric acid $(0,2,4,8$ and $12 \mathrm{mM})$. The tests used for evaluation were: standard germination, length of the aerial part, length of the root, dried mass of the aerial part and dried mass of the root. According to the results it was verified that the variable length of the root was the most responsive in all the 
acids and that the critical levels of toxicity of the acetic acid, propionic acid and butyric acid, that reduced $50 \%$ of the length of the root, were $9.0,6.5$ and $3.0 \mathrm{mM}$, respectively.

Key words: Avena sativa L., seeds, organic acids, toxicity

\section{Introdução}

A aveia branca (Avena sativa L.) é um dos mais importantes cereais, ocupando, em nível mundial, o sexto lugar em produção. É uma das espécies mais antigas cultivadas pelo homem no uso de seus grãos para alimentação humana e animal, pois apresenta um balanceamento de aminoácidos, vitaminas, minerais e carboidratos de alta qualidade, (Velloso e Federizzi, 2000). Embora o Brasil não seja conhecido mundialmente como produtor de aveia, é um dos países que ultimamente apresenta expansão considerável de área plantada com esta cultura, de aproximadamente 321,4 mil hectares (IBGE, 2007).

Apresenta-se como uma importante alternativa para participar do sistema de sucessão de culturas, devido a suas propriedades restauradoras do solo, tendo um papel fundamental em sistemas de semeadura direta. Assim, é uma excelente cultura para diversificação agrícola em regiões de monocultivo, como o sul do estado do Rio Grande do Sul, onde a cultura do arroz irrigado em sucessão com pastagens nativas predomina (Porto, 2007).

O sucesso da agricultura de um país têm sido dependente da disponibilidade e utilização de sementes e mudas de boa qualidade. No entanto, para esta cultura, observa-se uma escassa literatura referente ao controle de qualidade no processo de produção de sementes. $\mathrm{Na}$ produção de sementes, além do rendimento, deve ser dada ênfase à qualidade, pois este atributo tem fundamental significado na exploração econômica da pastagem, como também no campo de produção de sementes (Lucca Filho et al., 1999).

A Região Sul do Brasil apresenta uma área de 6,8 milhões de hectares, constituída por solos hidromórficos, representando $20 \%$ da área total do estado do Rio Grande do Sul (Pinto et al., 2004). Nestes solos, a maioria das espécies cultivadas tem seu desenvolvimento e produção prejudicada devido à má drenagem natural que provoca um ambiente anaeróbico, favorecendo a formação de substâncias tóxicas (Camargo et al., 1995). A deficiente drenagem dos solos hidromórficos destas áreas, favorece a ocorrência de condições anaeróbias que associada com a presença de matéria orgânica possibilita o desenvolvimento de microrganismos anaeróbios produzindo substância fitotóxicas. Com a incorporação de resíduos culturais ao solo antes de novo plantio, há potencialmente, a desvantagem de que produtos fitotóxicos, oriundos do metabolismo do material orgânico incorporado, possam exercer efeitos negativos, limitando a germinação e o estabelecimento das plântulas (Camargo et al., 2001).

Em condições anaeróbias, o problema é mais agravante, dada à baixa eficiência metabólica microbiana na conversão do carbono adicionado, levando a acumulação de compostos que afeta, de forma irreversível, a produtividade final das culturas estabelecidas nesse sistema (Brancher et al., 1996).

Dos numerosos compostos formados pelo metabolismo anaeróbico, destacam-se os ácidos orgânicos, especialmente os ácidos alifáticos de cadeia curta, como o acético, propiônico e butírico. $\mathrm{O}$ efeito tóxico desses ácidos depende do tipo e da concentração (Rao e Mikkelsen, 1977a), dentre os quais, que ocorrem na faixa de concentração de 0,1 a $14 \mathrm{mM}$ (Sousa, 2001) e, geralmente, na proporção de 6:3:1 respectivamente (Bohnen et al., 2005). Estes ácidos atingem valor máximo poucos dias após o alagamento, podendo ocorrer toxidez às plantas (Sousa e Bortolon, 2006). Essa toxidez é verificada nas fases iniciais do desenvolvimento da cultura, diminuindo a germinação, crescimento radicular, peso e altura das plântulas (Sousa, 2001).

A adoção do sistema de semeadura direta pode melhorar os atributos físicos do solo, e favorecer o desenvolvimento de culturas de sequeiro em solos de várzea. Porém, o excesso de resíduos vegetais na superfície do solo associado à drenagem deficiente pode favorecer o desenvolvimento de microsítios anaeróbios, 
onde a oxidação do carbono orgânico pode produzir os ácidos orgânicos acético, propiônico e butírico.

Para que o cultivo da aveia seja uma alternativa economicamente viável em solos de várzea se faz necessário à utilização de cultivares com tolerância aos principais ácidos orgânicos produzidos pela decomposição da matéria orgânica. Por isso, a importância deste trabalho reside na possibilidade de reconhecer os efeitos dos ácidos na qualidade fisiológica de sementes de aveia branca.

\section{Material e Métodos}

O trabalho foi conduzido no Laboratório Didático de Análises de Sementes, do Departamento de Fitotecnia, na Universidade Federal de Pelotas - Campus UFPel. Foram utilizadas sementes de aveia branca, cultivar UPF 16 (recomendada pela Comissão Brasileira de Pesquisa de Aveia); as quais foram submetidas aos testes de germinação $(\mathrm{G})$, comprimento da parte aérea (CPA), comprimento de raiz (CR), matéria seca da parte aérea (MSPA) e massa seca da raiz (MSR). Foram estudados os efeitos de cinco concentrações dos três principais ácidos formados no solo: ácido acético $(0 ; 4 ; 8 ; 12$ e $16 \mathrm{mM})$, ácido propiônico $(0 ; 4 ; 8 ; 12$ e $16 \mathrm{mM})$ e ácido butírico $(0 ; 2 ; 4 ; 8$ e $12 \mathrm{mM})$.

As sementes foram embebidas em soluções, com as respectivas concentrações acima mencionadas, por um período de $90 \mathrm{~min}$. Após, as sementes foram retiradas e colocadas em cima de papel toalha, para tirar o excesso da solução.

O teste de germinação foi realizado com quatro repetições de 100 sementes, semeadas em papel toalha (germitest) umedecido com água destilada, na proporção de 2,5 vezes o peso do papel seco. Conduzido em temperatura de $20^{\circ} \mathrm{C}$, sendo a contagem realizada no décimo dia após a semeadura, determinando-se a percentagem de plântulas normais e os resultados foram expressos em percentagem de plântulas normais (Brasil, 1992).

Avaliou-se o comprimento médio de 10 plântulas normais, escolhidas aleatoriamente, obtidas a partir da semeadura de quatro repetições de 20 sementes, no terço superior da folha de papel toalha. Os rolos de papel contendo as sementes permaneceram por cinco dias em germinador, temperatura de $20^{\circ} \mathrm{C}$, logo, se avaliou o comprimento da parte aérea e raiz das plântulas, com auxílio de uma régua milimetrada. O comprimento médio da raiz foi obtido somando-se as medidas de cada repetição e dividindo-se pelo número de plântulas normais e os resultados foram expressos em centímetros para a massa seca da raiz e da parte aérea. As plântulas foram seccionadas, separando-se o sistema radicular da parte aérea, que foram colocadas em cápsulas de alumínio, mantidas em estufa com convecção, regulada a $64^{\circ} \mathrm{C}$ durante $72 \mathrm{~h}$. Posteriormente foi avaliada a massa seca, utilizando-se balança de precisão $(0,0001 \mathrm{mg})$ e os resultados expressos em g.plântula-1 ${ }^{-1}$ Brasil, 1992).

As concentrações dos ácidos orgânicos foram analisadas separadamente, e os resultados foram submetidos à análise da variância, as médias sofreram comparação pelo teste de Tukey, em nível de 5\% de probabilidade, utilizando o programa de análises estatísticas Sisvar, (Ferreira, 2000) e análises de regressão.

\section{Resultados}

Os resultados apresentados na Tabela 1 demonstram que a cultivar UPF 16 não teve a germinação reduzida por nenhuma das doses testadas de ácido acético.

TABELA 1: Germinação (G) de sementes de aveia branca, submetidas ás concentrações de 0 ; $4 ; 8 ; 12$ e $16 \mathrm{mM}$ do ácido acético, no ano de 2008. Pelotas, RS.

\begin{tabular}{|c|c|c|c|c|c|c|}
\hline \multicolumn{7}{c}{ Concentração } \\
\hline & $\mathbf{0 m M}$ & $\mathbf{4 m M}$ & $\mathbf{8 m M}$ & $\mathbf{1 2 m M}$ & $\mathbf{1 6 m M}$ & $\mathbf{C V ( \% )}$ \\
\hline $\mathbf{G ~ ( \% )}$ & $88,0 \mathrm{a}$ & $87,0 \mathrm{a}$ & $88,0 \mathrm{a}$ & $87,0 \mathrm{a}$ & $88,0 \mathrm{a}$ & 1,53 \\
\hline
\end{tabular}

Médias seguidas pelas mesmas letras não diferem entre si pelo teste de Tukey a $5 \%$ de probabilidade.

O comprimento das raízes de aveia diminuiu sensivelmente com as doses crescentes de ácido acético (Figura 1) até a concentração máxima testada. Na fase inicial de desenvolvimento das plantas, o crescimento da raiz foi mais afetado que o crescimento da parte aérea. Por isso, o grau de toxidez dos ácidos orgânicos 
é avaliado pela redução do crescimento radicular. Para reduzir em $50 \%$ o crescimento do sistema radicular de aveia, foi necessária concentração de $9,0 \mathrm{mM}$ de ácido acético. Sousa (2001) verificou que para reduzir $50 \%$ o crescimento do sistema radicular da soja, a concentração de ácido acético foi de $2,0 \mathrm{mM}$. Para o sorgo, a quantidade de ácido acético que causou $50 \%$ de redução de crescimento da raiz foi de $1,8 \mathrm{mM}$.

O menor crescimento radicular ocorreu provavelmente porque o ácido acético afeta a integridade da membrana plasmática e interfere em processos de produção de energia na planta, como fosforilação oxidativa e respiração, de acordo com Armstrong e
Armstrong (2001). Segundo Freitas (2003), ácidos monocarboxílicos como o acético, alteram a composição dos ácidos orgânicos na membrana plasmática promovendo um decréscimo da proporção dos ácidos polisaturados afetando propriedades importantes da membrana, como a seletividade.

Para a variável comprimento da parte aérea e massa seca da parte aérea também foi verificada resposta diferencial das plântulas de aveia (Figura 2). No entanto, as reduções foram muito similares entre si, provavelmente com o resultado do menor crescimento radicular. O peso da massa seca da raiz não foi significativamente afetado (Figura 2).

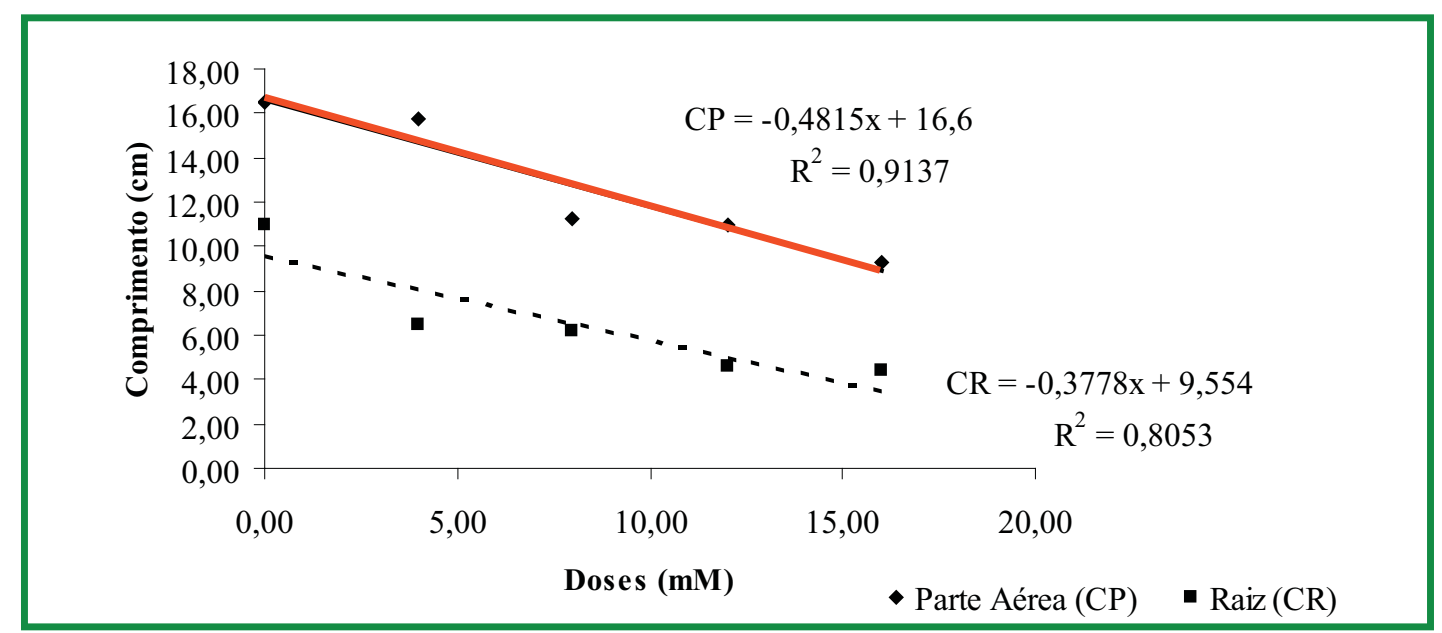

FIGURA 1: Média do comprimento da parte aérea e da raiz, de plântulas de aveia branca, submetidas às concentrações de $0 ; 4 ; 8 ; 12$ e $16 \mathrm{mM}$ do ácido acético, no ano de 2008. Pelotas, RS.

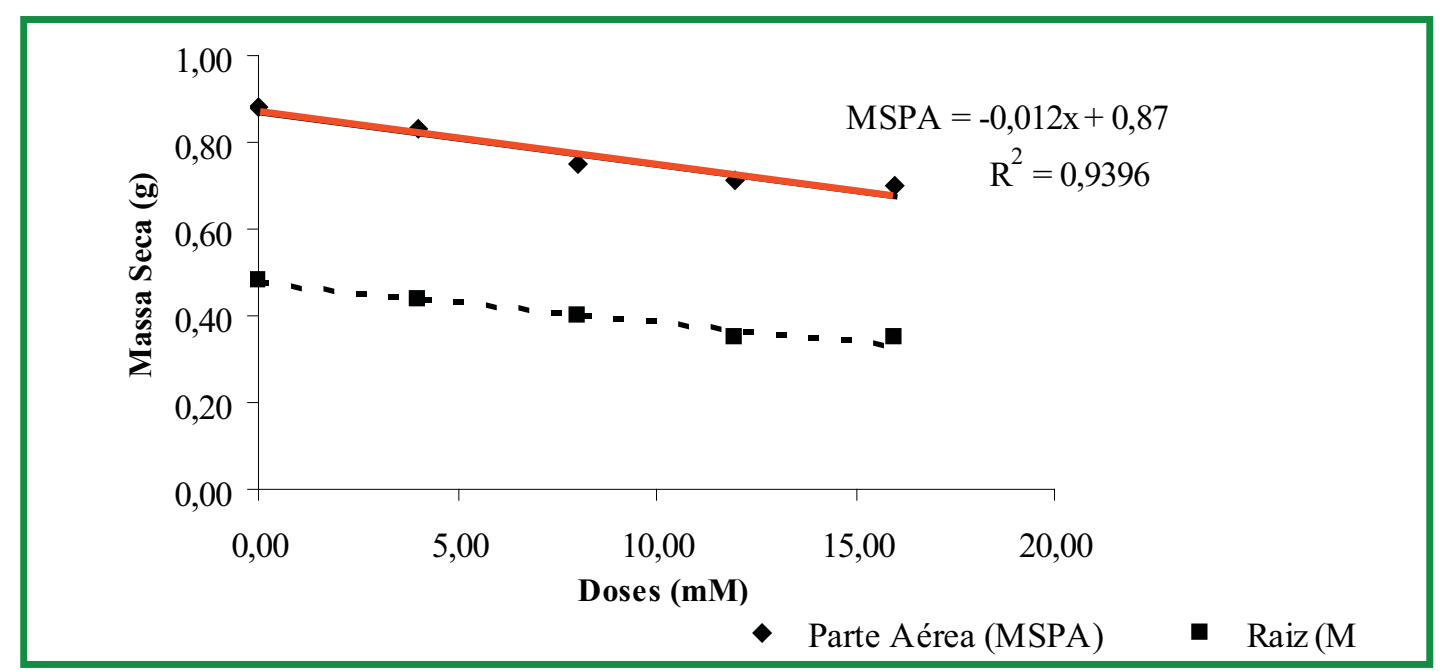

FIGURA 2: Média da massa seca do comprimento da parte aérea e da raiz, em plântulas de aveia branca, submetidas às concentrações de $0 ; 4 ; 8 ; 12$ e $16 \mathrm{mM}$ do ácido acético, no ano de 2008. Pelotas, RS. 
Para o ácido propiônico, houve diferença significativa nas concentrações de $12 \mathrm{mM}$ e $16 \mathrm{mM}$ em relação as demais, pois houve diminuição das percentagens de germinação (Tabela 2). No entanto, essas diferenças foram pouco expressivas, variando de 86 para $85 \%$ de germinação.

TABELA 2: Valores obtidos para germinação $(G)$ de sementes de aveia branca, submetidas às concentrações de $0 ; 4 ; 8 ; 12$ e $16 \mathrm{mM}$ do ácido propiônico, no ano de 2008. Pelotas, RS.

\begin{tabular}{|c|c|c|c|c|c|c|}
\hline \multicolumn{7}{|c|}{ Concentração } \\
\hline & $\mathbf{0 m M}$ & $\mathbf{4 m M}$ & $\mathbf{8 m M}$ & $\mathbf{1 2} \mathbf{m M}$ & $\mathbf{1 6 m M}$ & $\mathbf{C V ( \% )}$ \\
\hline $\mathbf{G ~ ( \% )}$ & $88,0 \mathrm{a}$ & $86,0 \mathrm{a}$ & $86,0 \mathrm{a}$ & $85,0 \mathrm{~b}$ & $85,0 \mathrm{~b}$ & 2,72 \\
\hline
\end{tabular}

Médias seguidas pelas mesmas letras, não diferem entre si pelo teste de Tukey a $5 \%$ de probabilidade.
Com relação à ação fitotóxica do ácido propiônico, os ajustes de regressão (Figura 3) demonstram que o comportamento médio das variáveis foi similar ao evidenciado com ácido acético. A variável comprimento da raiz foi a de maior responsividade, com redução significativa a partir da dose de $4 \mathrm{mM}$. Pode ser constatado, que a variedade apresentou resposta diferencial apenas para a variável comprimento da raiz.

Com o incremento da dose de ácido propiônico houve uma redução linear da massa seca da parte aérea e principalmente da massa seca da raiz (Figura 4).

A germinação da aveia diminuiu pelas concentrações maiores que $8 \mathrm{mM}$ de ácido butírico (Tabela 3).

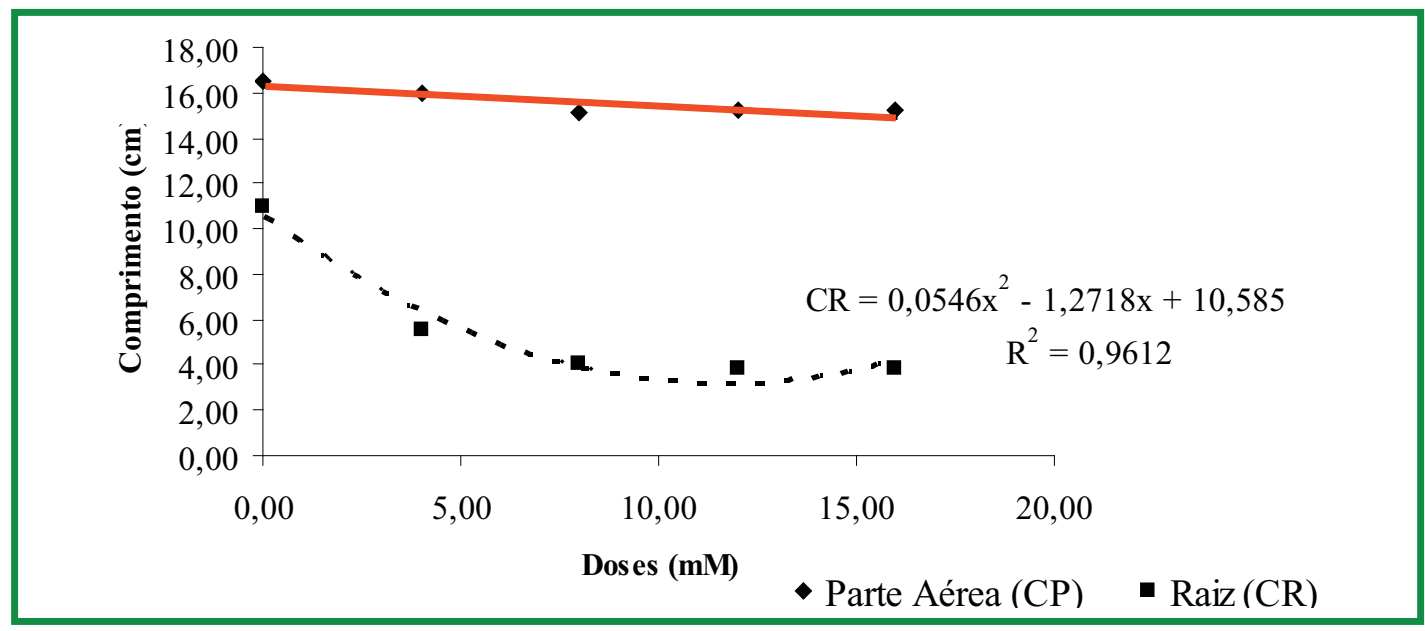

FIGURA 3: Média do comprimento da parte aérea e da raiz, em plântulas de aveia branca, submetidas às concentrações de 0; 4; 8; 12 e $16 \mathrm{mM}$ do ácido propiônico, no ano de 2008. Pelotas, RS.

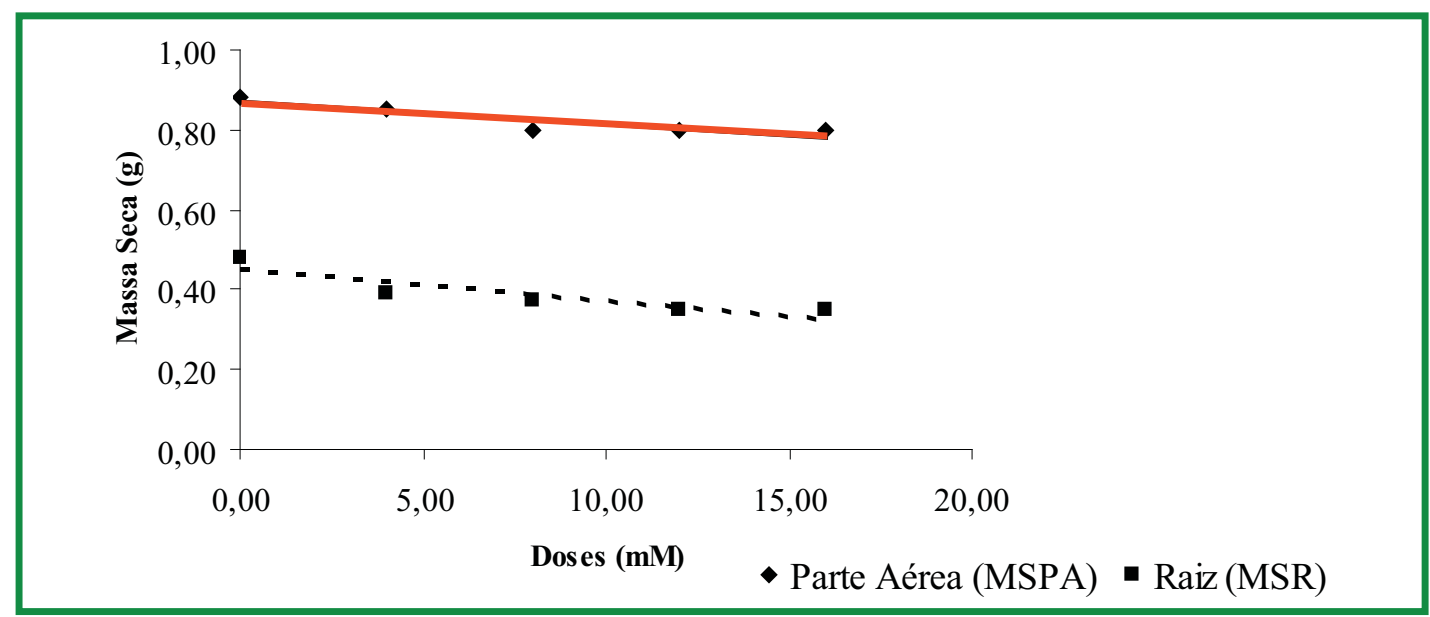

FIGURA 4: Média da massa seca do comprimento da parte aérea e da raiz, em plântulas de aveia branca, submetidas às concentrações de 0; 4; 8; 12 e 16mM do ácido propiônico, no ano de 2008. Pelotas, RS. 
TABELA 3: Valores obtidos para germinação $(G)$ de sementes de aveia branca, submetidas às concentrações de $0 ; 2 ; 4 ; 8$ e $12 \mathrm{mM}$ do ácido butírico, no ano de 2008. Pelotas, RS.

\begin{tabular}{|c|c|c|c|c|c|c|}
\hline \multicolumn{7}{|c}{ Concentração } \\
\hline & $\mathbf{0 m M}$ & $\mathbf{2 m M}$ & $\mathbf{4 m M}$ & $\mathbf{8 m M}$ & $\mathbf{1 2 m M}$ & $\mathbf{C V ( \% )}$ \\
\hline $\mathbf{G} \mathbf{( \% )}$ & $88,0 \mathrm{a}$ & $87,0 \mathrm{a}$ & $88,0 \mathrm{a}$ & $85,0 \mathrm{~b}$ & $83,0 \mathrm{c}$ & 1,37 \\
\hline
\end{tabular}

Médias seguidas pelas mesmas letras, não diferem entre si pelo teste de Tukey a $5 \%$ de probabilidade.
A variável comprimento da raiz foi a que apresentou maior redução (Figura 5), chegando, por exemplo, a um decréscimo de aproximadamente $50 \%$ na dose de $3 \mathrm{mM}$. Também foi verificada a redução do comprimento da parte aérea com o aumento da dose do ácido butírico. As variáveis massa seca da raiz e massa seca da parte aérea (Figura 6) tiveram reduções com o aumento das concentrações do ácido butírico. Entretanto, também pode ser evidenciado que o decréscimo da massa seca da parte aérea foi menor do que a massa seca da raiz.

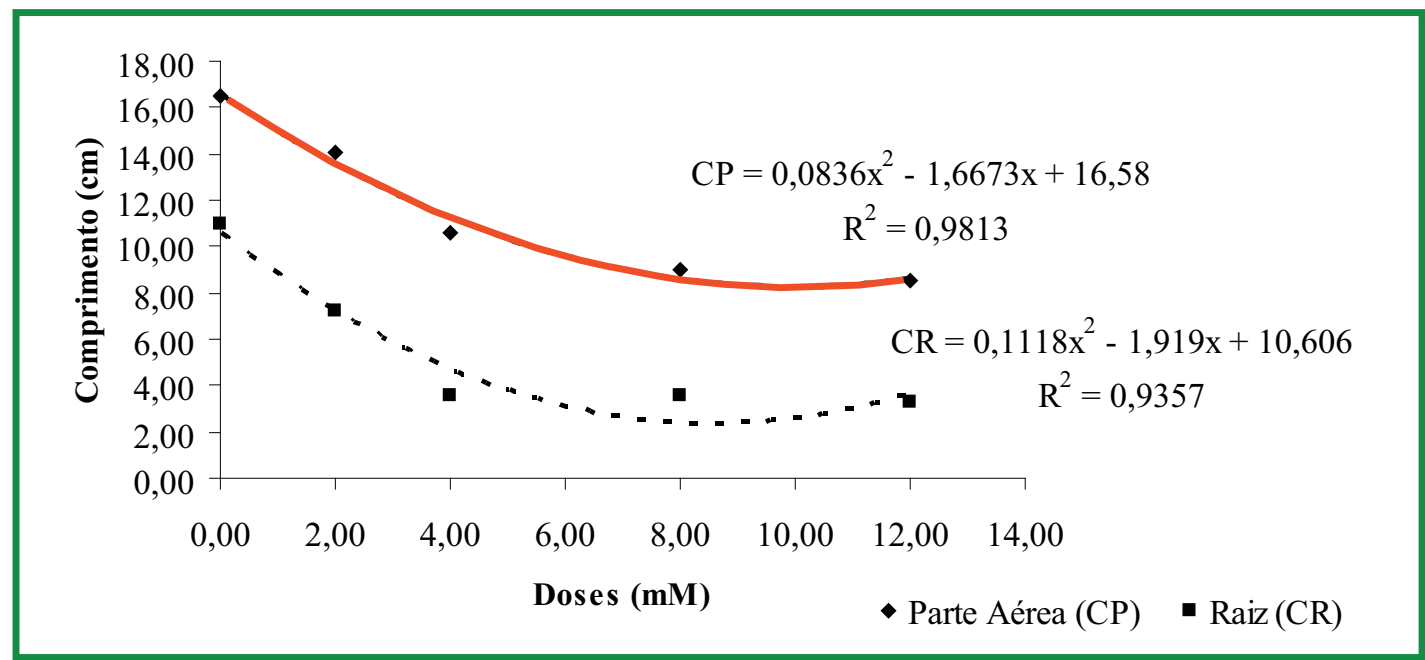

FIGURA 5: Média do comprimento da parte aérea e da raiz, em plântulas de aveia branca, submetidas às concentrações $0 ; 2 ; 4 ; 8$ e 12mM do ácido butírico, no ano de 2008. Pelotas, RS.

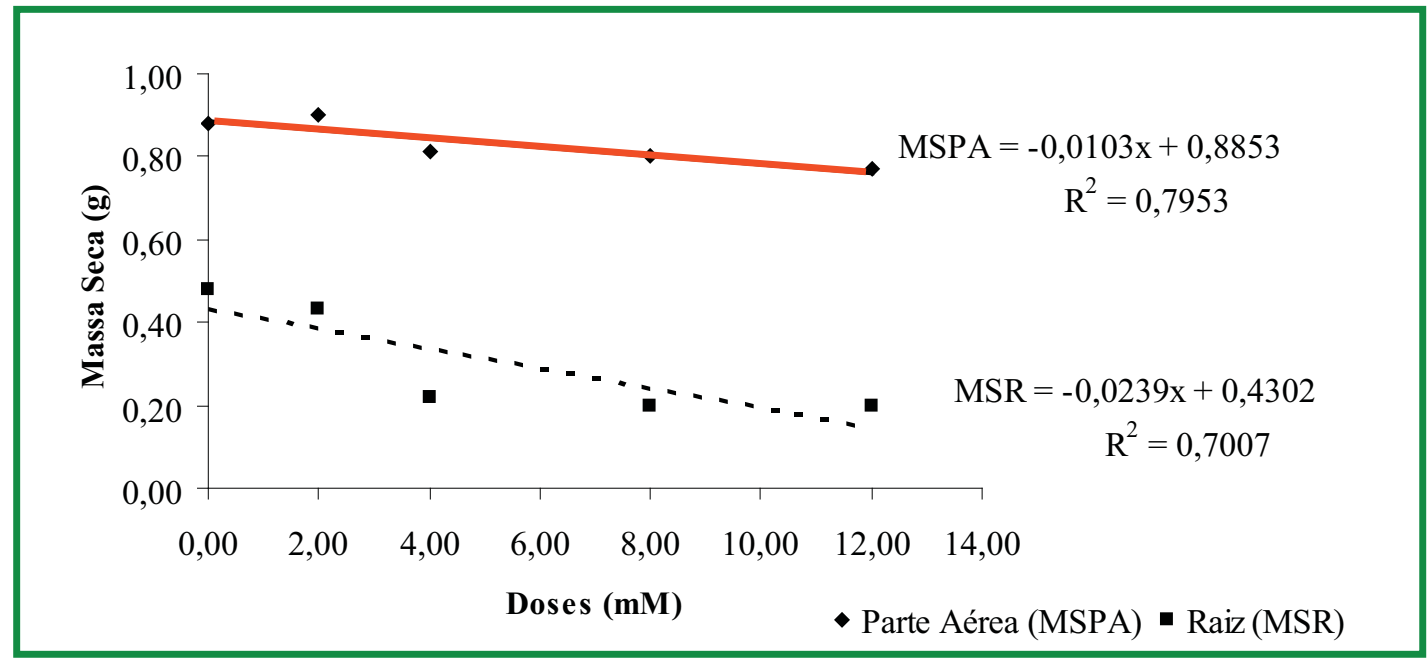

FIGURA 6: Média da massa seca do comprimento da parte aérea e da raiz, em plântulas de aveia branca, submetidas às concentrações 0 ; 2; 4; 8 e 12mM do ácido butírico, no ano de 2008. Pelotas, RS. 


\section{Discussão}

Os níveis utilizados neste experimento foram selecionados a partir de estudos anteriores, que concluíram que a fitotoxidez dos ácidos orgânicos aumenta na ordem: acético, propiônico e butírico, pois, quanto maior o tamanho da cadeia de carbonos do ácido, mais tóxico ele será, segundo Takijima (1964); Rao e Mikkelsen (1977a e b) e Krogmeier e Bremner (1990). Os resultados sugerem que o ácido acético, de fato, se mostrou menos tóxico, pois para promover uma redução de 50\% no comprimento de raízes (variável mais afetada) uma concentração de $9,0 \mathrm{mM}$ foi necessária. No entanto, para os ácidos propiônico e butírico, concentrações de 6,5 e 3,0mM, respectivamente, foram suficientes para promover reduções de aproximadamente $50 \%$ no comprimento de raízes. Assim, pode ser constatado que o ácido butírico é o mais fitotóxico, no entanto com maior diferença em relação ao ácido propiônico.

No trabalho de Takijima (1964), a concentração de 5,0mM de ácido acético se mostrou prejudicial ao arroz, pois causou $50 \%$ de redução do crescimento radicular e $18 \%$ de redução do crescimento da parte aérea. Badinelli e Tunes (2008) afirmam que os ácidos butírico e propiônico são os que apresentam maior concentração no solo e predominam por maior tempo, por isso, observar o comportamento das sementes frente a esses ácidos é essencial para analisar a sua capacidade de tolerância.

Badinelli e Tunes (2008) estudaram as concentrações do ácido acético, butírico e propiônico na cultivar de aveia URS 23 e também verificaram que, á medida que aumenta a concentração dos ácidos orgânicos, ocorre à diminuição tanto do comprimento como o peso da matéria seca das raízes, concluindo que esses ácidos prejudicam a qualidade fisiológica das sementes de aveia.

Estes resultados concordam com os obtidos por Rao e Mikkelsen (1977b) que verificaram maiores reduções no comprimento de raízes em arroz sob efeito dos ácidos orgânicos. A massa seca das raízes também apresentou desempenho relativo baixo com o aumento das concentrações utilizadas nos tratamentos. Armstrong e Armstrong (2001) estudaram os sintomas fisiológicos relacionados à toxidez destes ácidos em arroz e relataram que estes causam degradação da parede celular, inibição das funções respiratórias e conseqüente diminuição da divisão celular do sistema radicular que está em contato direto com estes ácidos, indicando assim a razão principal para o menor crescimento radicular e acúmulo de matéria seca.

O comprimento da parte aérea apresentou desempenho elevado, contrariando os resultados obtidos por Camargo et al. (1993), que obtiveram desempenho semelhante ao comprimento da raiz. Isto pode ser devido à plântula em estágios iniciais apresentar reservas nutritivas da semente, e com a diminuição do desenvolvimento radicular, ocorra um acúmulo de reserva na parte aérea, o que ocasionaria uma diminuição da resposta a toxicidade dos ácidos orgânicos.

De acordo com Neves et al. (2007), para medir os efeitos dos ácidos acético, butírico e propiônico no vigor das sementes, é necessário utilizar testes de germinação e de viabilidade (comprimento de plântulas e peso da matéria seca). Afirma que a presença de mais de quatro toneladas por hectare de massa verde, há probabilidade de prejudicar seriamente a germinação das sementes de arroz e as culturas alternativas de inverno semeadas em áreas orizícolas, como aveia e trigo. Os resultados mostraram que soluções dos ácidos orgânicos em água, com volume superior a quantidade de $12 \mathrm{mM}$, reduzem significamente a germinação. De acordo com Neves, isso corresponderia a cerca de duas a três toneladas por hectare de massa verde em solos sob inundação, como o do arroz.

A variável comprimento de raízes foi a mais eficiente em discriminar a resposta da cultivar frente ao estresse causado pelos ácidos acético propiônico e butírico. As variáveis comprimento de parte aérea, matéria seca de raízes e matéria seca de parte aérea também são indicadas para estudos com ácido acético e a variável comprimento de parte aérea, em estudos com ácido butírico.

O efeito fitotóxico é dependente do comprimento da cadeia de carbonos e concentração desses ácidos. O sistema radicular, na fase inicial do crescimento vegetal, é a estrutura mais afetada, principalmente, o 
alongamento radicular. Esses sintomas estão associados à inibição à respiração, com conseqüente inibição da divisão celular.

\section{Agradecimentos}

À CAPES pela concessão da bolsa de estudos. Ao curso de pós-graduação em Fitotecnia, área de concentração, Ciência e Tecnologia de Sementes da UFPel.

\section{Referências}

Armstrong, J.; Armstrong, W. 2001. Rice and Phragmites: effects of organic acids on growth, root permeability, and radial oxygen loss to the rhizosphere. American Journal of Botany, 88 (8): 13591370.

Badinelli, P. G.; Tunes, L. M. 2008. Avaliação de diferentes concentrações do ácido acético, propiônico e butírico em sementes de aveia branca. Anais da Reunião da Comissão Brasileira de Pesquisa de Aveia, Pelotas, Brasil, p.322-328.

Bohnen, H.; Silva, L. S.; Macedo, V. R. M.; Marcolin, E. 2005. Ácidos orgânicos na solução de um gleissolo sob diferentes sistemas de cultivo com arroz irrigado. Revista Brasileira de Ciência do Solo, 29 (3): 475-480.

Brancher, A.; Camargo, F. A. O.; Santos, G. A. 1996. Occurrence of physiological disease in flooded rice fields. Ciência Rural, 26 (1): 149-151.

Brasil, Ministério da Agricultura e Reforma Agrária. 1992. Regras para análise de sementes. SNDA/DNDV/ CLAV, Brasília, Brasil, 365pp.

Camargo, F. A. O.; Santos, G. A.; Rossiello, R. O. P. 1993. Efeito dos ácidos acético e butírico sobre o crescimento de plântulas de arroz. Pesquisa Agropecuária Brasileira, 28 (9): 1011-1018.

Camargo, F. A. O.; Santos, G. A.; Rossiello, R. O. P.; Zonta, E. 1995. Incorporação de palha de arroz em um gleissolo e efeitos no rendimento da cultura do arroz irrigado. Pesquisa Agropecuária Brasileira, 30 (7): 983-987.

Camargo, F. A.; Zonta, E.; Santos, G. A.; Rossielo, R. O. P. 2001. Aspectos fisiológicos e caracterização de toxidez a ácidos orgânicos voláteis em plantas. Ciência Rural, 31 (3): 523-529.
Ferreira, D. F. 2000. Análises estatísticas por meio do Sisvar para Windows versão 4.0. Anais da Reunião Anual da Região Brasileira da Sociedade Internacional de Biometria, São Paulo, Brasil, p.255-258.

Freitas, F. A. 2003. Dissimilaridade genética em arroz (Oryza sativa L.) quanto à toxicidade ao alumínio. Dissertação de Mestrado, Universidade Federal de Pelotas, Brasil, 69pp.

IBGE. 2007. Levantamento sistemático de produção agrícola. Disponível em <http:// www.ibge.com.br/home/estatistica/indicadores/agropecuaria>. Acesso em 11 de maio de 2007.

Krogmeier, M. J.; Bremner, J. M. 1990. Effects of aliphatic acids on seed germination and seedling growth in soil. Communications in Soil Science and Plant Analysis, 21 (7): 547-555.

Lucca Filho, O. A.; Porto, M. D. M.; Maia, M. S. 1999. Fungos em sementes de azevém-anual (Lolium multiflorum Lam.), Revista Brasileira de Sementes, 21 (2): 142-147.

Neves, L. A. S.; Moraes, D. M.; Lopes, N. F.; Abreu, C. M. 2007. Vigor de sementes e atividade bioquímica em plantas de arroz submetidas a ácidos orgânicos. Pesquisa Agropecuária Gaúcha, 1-2 (13): 79-80.

Pinto, L. F. E.; Laus, J. A.; Pauletto, E. A. 2004. Solos de várzea no sul do Brasil. In: Gomes, A. S. \& Magalhães Jr., A. M. (Eds). Arroz irrigado no sul do Brasil. EMBRAPA, Pelotas, Brasil, p.75-95.

Porto, M. P. 2007. Método de seleção de plantas de milho para tolerância ao encharcamento do solo. Pesquisa Agropecuária Gaúcha, 13 (4): 1-2.

Rao, D. N.; Mikkelsen, D. S. 1977a. Effect of acetic, propionic, and butyric acids on young rice seedlings growth. Agronomy Journal, 69 (6): 923-928.

Rao, D. N.; Mikkelsen, D. S. 1977b. Effect of acetic, propionic, and butyric acids on rice seedlings growth. and nutrition. Plant and Soil, 47 (6): 323-334.

Sousa, R. O. 2001. Oxirredução em solos alagados afetada por resíduos vegetais. Tese de Doutorado, Universidade Federal do Rio Grande do Sul, Brasil, 164pp.

Sousa, R. O.; Bortolon, L. 2006. Crescimento radicular e da parte aérea do arroz (Oryza sativa L.) e absorção de nutrientes em solução nutritiva com diferentes concentrações de ácido acético. Revista Brasileira de Agrociência, 8 (3): 231-235.

Takijima, Y. 1964. Growth inhibiting action of organic acids and absorption and decomposition of them by soils. Soil Science Plant Nutrition, 12 (4): 435-442.

Velloso, C. B. O.; Federizzi, L. C. 2000. Delimitação preliminar da cadeia da aveia branca para consumo humano no Brasil. Resultados Experimentais da $\mathrm{XX}^{\mathrm{a}}$ Reunião da Comissão Brasileira de Pesquisa de Aveia, Pelotas, Brasil, p.181-183. 